Research Article

\title{
Testing the Correlation between Prior Knowledge of - and Visualisation Guided WTPs for Reducing the Visual Impacts Visual from Offshore Wind Farms
}

\author{
Jacob Ladenburg *
}

The ROCKWOOL Foundation Research Unit, Ny Kongensgade 6, Copenhagen, Denmark; Email: jla@rff.dk

* Correspondence: Jacob Ladenburg; E-Mail: jla@rff.dk

Academic Editor: Andrés Elías Feijóo Lorenzo

Special Issue: Offshore Wind Farms

Journal of Energy and Power Technology

2020, volume 2 , issue 3

doi:10.21926/jept.2003015
Received: April 28, 2020

Accepted: July 30, 2020

Published: August 12, 2020

\begin{abstract}
Visual external costs are significant elements in the cost-benefit analysis of wind farm locations. This has been demonstrated well in the literature. However, in the assessment of the visual costs, a large share of the earlier studies used no or only simplistic visualizations of the visual impacts at stake. The cost estimates thus rely on the respondents' ability to imagine the visual impacts associated with wind turbines of different sizes and at different locations. This has been argued to potentially reduce the validity of the visual cost estimates. The present paper analyzes whether respondents' prior perceptions of the visual impacts from offshore wind farms correlate with their stated preferences for reducing the same visual impacts from offshore wind farms, when presented with visualizations of the visual impacts. The results show that respondents who perceive offshore wind farms to have positive or neutral visual impacts express equally strong preferences and high positive willingness to pay for reducing visual impacts, compared to respondents who perceive the visual impacts to be negative. The information in the visualizations thus appears to have updated the prior perception of the visual impacts of offshore wind farms.
\end{abstract}

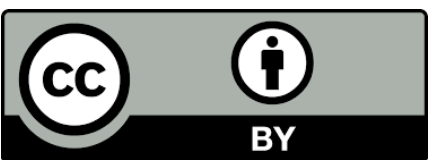

(C) 2020 by the author. This is an open access article distributed under the conditions of the Creative Commons by Attribution License, which permits unrestricted use, distribution, and reproduction in any medium or format, provided the original work is correctly cited. 


\section{Keywords}

Offshore wind farms; visual impacts; use of visualizations; update of prior perceptions; choice experiments

\section{Introduction}

The development of wind power, and particularly offshore wind power, has increased drastically in the fight against global warming [1]. However, with more turbines being built, more people are exposed to their impacts. These impacts are particularly visual impacts and noise disturbances, and they lead to external costs of wind power [2-6].

The external costs have increased the need for having them quantified. The economic values of the impacts can guide policy-makers in making the difficult trade-offs between the technical/generation advantages of different wind farm sites and the associated external costs. The increase in demand for quantification has motivated researchers around the world to carry out Stated Preference (SP) economic valuation studies for assessing the external costs of wind power. So far, more than 25 such studies have been published.

As highlighted by Hevia-Koch and Ladenburg [7], the use of visualizations and the quality of those visualizations might be imperative for the validity of the estimated acceptance costs. The authors argue that unless the respondents have well updated prior information regarding the visual impacts of wind farms, they rely heavily on the use of visualizations in surveys. The need for visualizations is even more important, if the SP studies wish to take into account the visual impacts related to shadow effects/flickering and nighttime illumination [8-10]. Following the recommendations of Arrow et al. [11], Bateman et al. [12], and Champ et al. [13], the designers of SP studies must assure that the respondents are provided with the best tools possible to state valid and trustworthy preferences. This includes a thorough description and presentation of the attributes of the goods under investigation. Accordingly, "descriptions may require a combination of textual information, photographs, drawings, maps, charts, and graphs" [12].

The use of visualizations is of particular importance if the respondents have little knowledge on the good being valued. For example, Hoehn and Randall [14] find that varying the information about the quality and level of the good in focus in an SP study has an influence on the stated preferences. Another example is the research done by Czajkowski et al. [15]. Their test is about the quantum of knowledge that the respondents have about the good in focus. Interestingly, according to their findings, only $2.2 \%$ of the respondents have a high level of prior information. However, they also find that $59.1 \%$ have a low level of information. Finally, Kataria and co-authors [16] asked respondents about their perceptions of the current water quality in a river. Only $66 \%$ of the respondents had the objectively correct perception of the ecological quality of the river.

In complex choice situations, the influence of pictures and diagrams on choices has been tested. In the field of cognitive and educational psychology, if the information given is conveyed with diagrams [17] then the performance is improved. Hoehn et al. [18] tested two scenario information formats (text only and text, including tabular data). The tabular format both reduced the use of choice heuristics as well as the variance of the estimated preference parameters. Just recently, Shr et al. [19] have found that a combination of both visual and textual representations 
increases willingness to pay (WTP) for visual attributes compared to texts or visuals alone. This suggests that visualizations matter and might update the prior information about visual attributes. Another study by Patterson et al. [20] also finds similar results. The study compares preferences among respondents, who were represented to text-alone or a virtual reality experiment. They conclude that the preferences based on text-alone depend upon the respondents' mental images. The preferences are based on the images displayed in the virtual reality experiment. In a study by Rid et al. [21], 2D still pictures are compared to 3D movie sequences in relation to preferences for housing development. The 2D images provide more significant parameters. Matthews et al. [22] also tested virtual reality relative to $2 \mathrm{D}$ images. The study found that virtual reality, relative to $2 \mathrm{D}$ pictures, reduced choice error, lessened left-right bias, and improved respondent engagement and retention. Past studies reveal that preferences and choices are sensitive to the type of visualizations. Particularly, the study by Patterson et al. [20] and their conclusions are much in line with the aim of the present paper.

This paper aims to test if initial (prior) perceptions of the visual impacts from offshore wind farms correlate with visualization-guided stated preferences for reducing the same visual impacts. The analyses denote that irrespective of whether respondents initially perceive the visual impacts from offshore to be positive, neutral, or negative, all three groups of respondents express equally high positive WTP for reducing those specific visual impacts. Accordingly, the respondents seem to have their prior knowledge of the visual impacts of offshore wind farms updated by the visualizations given when stating the preferences and WTP for reducing the visual impacts from offshore wind farms. In application, these results indicate the importance of policy-makers and energy researchers in paying attention to the level of prior information regarding wind power in the population, while choosing an appropriate tool to assess the visual costs of wind power.

The paper is structured as follows: first, the survey and the theoretical model are presented; this is followed by the results, discussion, and conclusion.

\section{Materials and Methods}

\subsection{Survey}

The comparison of perceptions of visual impacts from offshore wind farms and the visualization-guided preferences for reducing them is based on a sample consisting of 700 randomly selected individuals between the age of 20 and 65 [23, 24], drawn from the Danish Civil Registration System's database. Information on the perceptions and preferences for the visual impacts was collected by mail-delivered questionnaires. In May 2004, each respondent received a cover letter and an 11-page questionnaire. Two reminders that did not include a new questionnaire were mailed to the respondents who had failed to respond. In total, 353 usable questionnaires were returned, which is equal to an effective response rate of $51 \%{ }^{1}$

In the questionnaire, each respondent was presented with a series of questions regarding wind power, the perception of impacts from wind power, an economic valuation scenario, and questions relating to the socioeconomic characteristics of the respondents (in that order). ${ }^{2}$ The interest of this paper is in the perception of the visual impacts from offshore wind farms and the

\footnotetext{
${ }^{1}$ Compared to [23], respondents, who have not answered all the three choice sets, are excluded.

2 The applied questionnaire is available in Ladenburg et al. [24]
} 
economic valuation scenario, which includes visualizations. These are presented in the next two sections.

\subsubsection{Perceptions}

The information on the individual perceptions of the visual impacts from offshore wind farms was obtained from a single question. The respondents were asked to state their perceptions of the visual impacts from offshore wind farms on a five-point Likert-like scale with an additional option of an "I do not know" answer. Besides this, the visual impact scale ranged from "very positive", "mainly positive", "neutral", "mainly negative" and "very negative". The perception question was asked before the preference elicitation part of the questionnaire. Respondents who answered, "I do not know" are not included in the analysis.

\subsubsection{Preferences}

The economic valuation method, Choice Experiment (CE), was applied to elicit preferences for reducing the visual impacts from offshore wind farms $[25,26]$. In short, CE is an economic valuation technique that has been applied in the field of marketing since the early seventies. It has been used in more than ten published papers focusing on offshore costs of wind power, see $[4,7$, 27] for specific reviews of SP wind power studies.

In a $\mathrm{CE}$, respondents were presented with a set of hypothetical "packages" with different characteristics, also called attributes. These packages also referred to as alternatives, and they are alternative provisions of the good in focus. In the present case, good refers to different levels of visual impacts from offshore wind farms. Respondents may choose their preferred alternatives from three choice sets. The choices reflect the respondents' trade-offs between different attributes. CE builds on the theory proposed by Lancaster [28] and Rosen [29], where the bundle of attributes that the good consist of, gives utility to the consumer. If a cost attribute is included, the WTP for the different attributes, such a reduction in visual impacts from offshore wind farms, can be estimated.

The Danish offshore wind power development plan of 1996 forms the basis of the policy scenario under evaluation in the CE. It stipulated that, by 2030, 35\% of Danish electricity consumption should come from wind power [30]. Further, 4,000 MW of power was expected to be developed offshore. At the time of the survey, the offshore wind power capacity was $\sim 400 \mathrm{MW}$. Accordingly, the scenario entailed an offshore expansion of 3,600 MW of power. Turbines of 5 MW (100 m high and $120 \mathrm{~m}$ wingspan) were used in the valuation scenario. Consequently, the scenario entails the installation of $720(720 \times 5=3,600 \mathrm{MW})$ turbines offshore.

In order to represent the visual impacts, the attributes chosen were the distance from the coast and the size of the wind farm. The choices of attribute levels were made on recommendations from focus groups' interviews, the members of an Environmental Steering Group of the CE project, and offshore wind power developers. In short, distances of $8 \mathrm{~km}, 12 \mathrm{~km}$, and $18 \mathrm{~km}$ from the shore were considered as being realistic distances where future offshore wind farms could be located at. The distance of $50 \mathrm{~km}$ is the technical distance from where a $5 \mathrm{MW}$ wind turbine cannot be seen from the shore due to the curvature of the earth. The number of turbines $(49,100$, and 144) represents the possible wind farm sizes. To reach the target of 3,600 MW offshore wind power capacity, the number of $5 \mathrm{MW}$ turbines in the scenario must be $\sim 720$ turbines. Accordingly, the 
number of turbines per wind farm and the total number of farms correlate almost perfectly (14 wind farms $\times 49$ wind turbines/wind farm $=686$ turbines, 7 wind farms $\times 100$ wind turbines/wind farm $=700$ wind turbines, and 5 wind farms $\times 144$ turbines/wind farm $=720$ turbines). The visual impacts associated with the wind farms of different sizes at different distances were illustrated by generic [7] computer-based visualizations. These were created by a specialist consultancy company. An example of the visualizations and a choice set is presented in Figure 1.

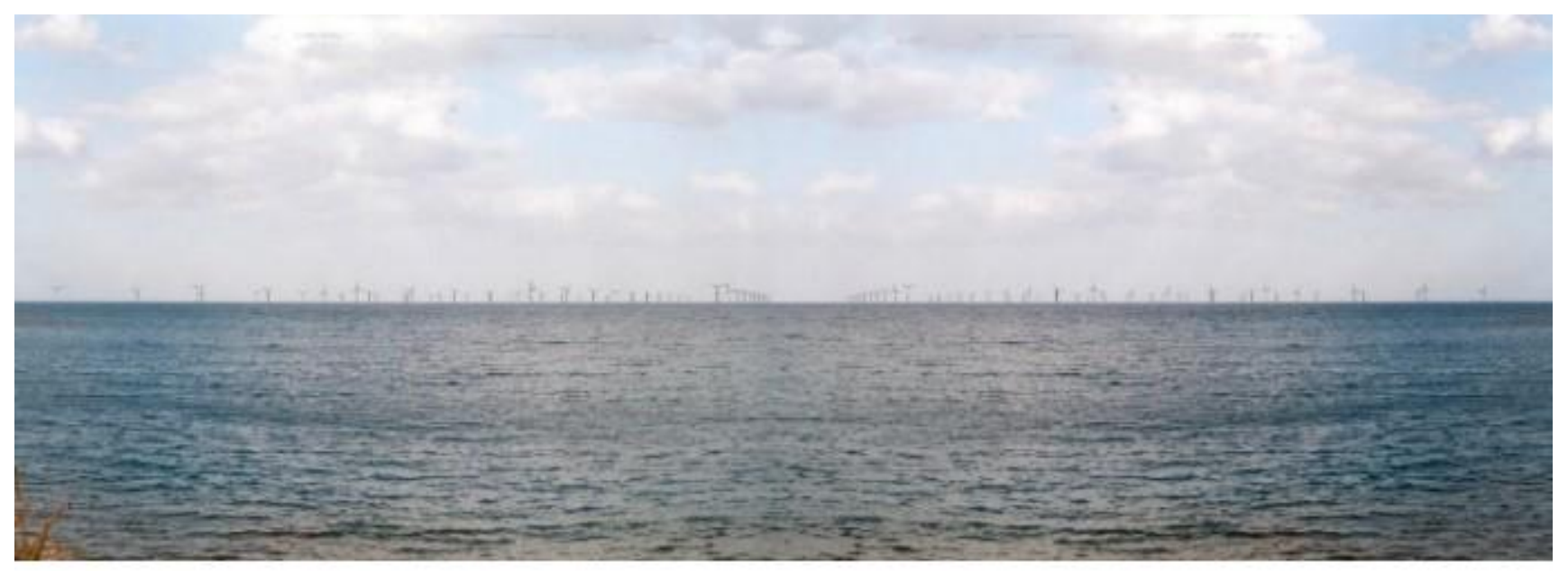

Alternative A

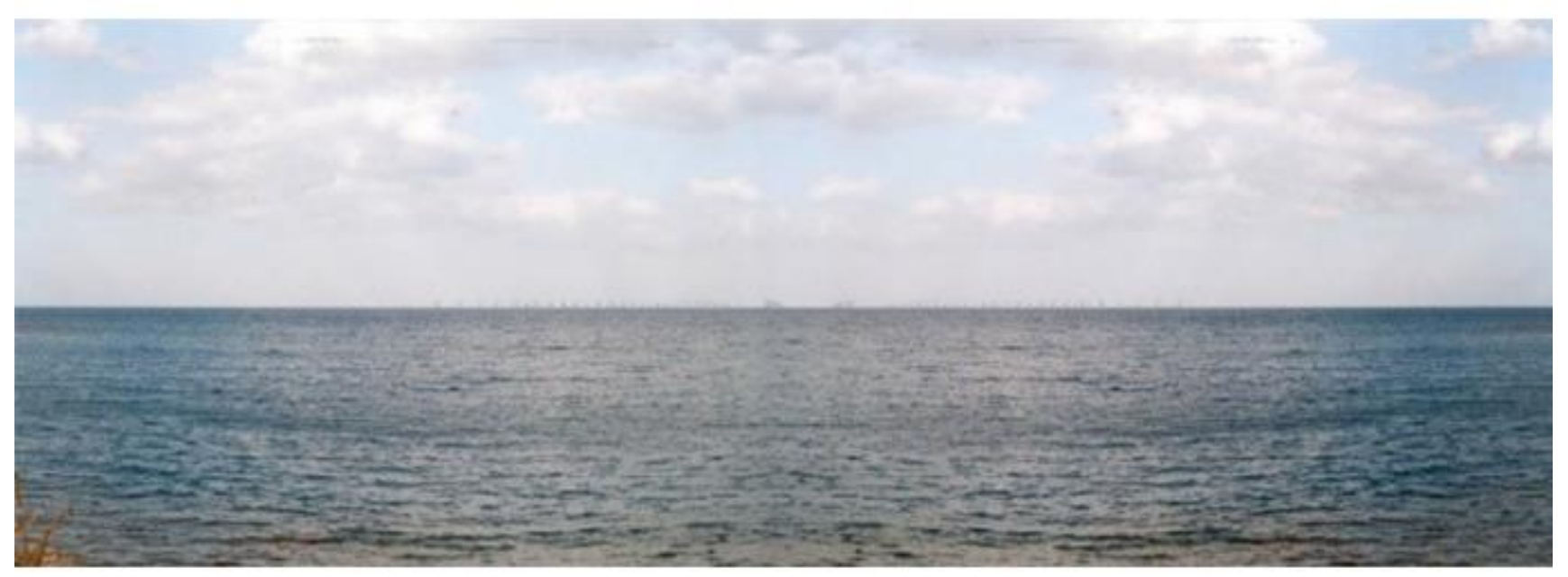

Alternative B

Figure 1 Example of the choice set. Alternative A Distance: 8 km, No. Turbines:100, No. Wind farms: 7 and Cost: 40 euro/year. Alternative B Distance: 18 km, No. Turbines:100, No. Wind farms: 7 and Cost: 80 euro/year.

\section{Choose $\quad$ A $\square \quad$ B $\square$}

In order to facilitate the payment for reducing the visual impacts on the hypothetical market in the scenario description, a uniform annual surcharge (lump sum) on all the households' electricity bills was realized. To minimize hypothetical bias, the respondents were prompted to be absolutely sure that their household would be willing to pay the amount specified, and a relatively short 
version of a "Cheap Talk" reminder was included [31, 32] $]^{3}$. The text given to the respondent is presented in the Appendix.

\subsection{Theoretical Model of the Link between Prior Perceptions and Update Preferences}

From the two previous sections, the two processes of elicitation of perception and preferences are distinct. The perception question is short, simple, and solely relies on the prior knowledge that the respondents have on the visual impacts of offshore wind farms. The preference question entails information given to the respondent, advice with regard to how to state a rational preference (budget reminders and cheap talk), and visualizations. In other terms, the perception statements are based on the respondents' perceived prior knowledge with regard to the visual impacts from offshore wind farms, whereas stated preferences are based on a combination of prior knowledge, visualizations, and written information. This framework strongly links to the paper by Blomquist and Whitehead [33], where the perception of the value of a good is a function of the prior information and information given to the individual at the time of a choice decision. Following Blomquist and Whitehead [33], for a representative agent, the perceived quality $q$ of a good can be expressed in terms of the actual quality of the good $\theta$ and the information received during the survey regarding the good's quality $I$ is:

$$
q=\widetilde{\beta \cdot \theta}+\widetilde{\delta \cdot I}
$$

Both the actual quality of the good and the information received during the survey depend upon the individual learning parameters $\beta$ and $\delta$, respectively. These learning parameters do not directly refer to how much information the respondent is provided with; they merely represent the capability of the respondent to absorb this information. The learning parameters may be a function of personal characteristics [34], how motivated the respondent is for processing the information [35], how relevant and available the information is [14, 36], differences in how much prior information the respondent has about the good in focus [37, 38], or the type/quality of the information medium chosen [14, 33, 34]. The total amount of prior information on the resource quality, the respondent has, is represented by $\beta \cdot \theta$. Likewise, the total impact information provided in the survey has on the respondents' perception of the good in focus is represented by $\delta \cdot I$. Blomquist and Whitehead [33] developed their model in relation to the standard SP method-Contingent Valuation Method (CVM) [37, 39] study framework. Accounting for the different attributes in a $\mathrm{CE}$, the quality changes under evaluation become a function of the values of $n$ attributes and, therefore, the terms of Eq. (1) can be expressed as vectors:

$$
\begin{gathered}
q=\boldsymbol{\beta} \cdot \boldsymbol{\theta}+\boldsymbol{\delta} \cdot \boldsymbol{I} \\
=\left[\beta_{1}, \ldots, \beta_{n}\right] \cdot\left[\theta_{1}, \ldots, \theta_{n}\right]+\left[\delta_{1}, \ldots, \delta_{n}\right] \cdot\left[I_{1}, \ldots, I_{n}\right]
\end{gathered}
$$

Where every term of the vector $\boldsymbol{\theta}$ represents the objective change in quality related to a specific attribute of the good. Likewise, $I$ represents the information about a specific attribute of the good that the respondent receives in the CE. In our case, we have two visual attributes: the distance to the coast (D) and the number of turbines $(N)$ in each wind farm. These changes (2) to (3)

\footnotetext{
${ }^{3}$ The CT is marked with bold letters in the preamble.
} 


$$
q=\left[\beta_{N}, \beta_{D}\right] \cdot\left[\theta_{N}, \theta_{D}\right]+\left[\delta_{N}, \delta_{D}\right] \cdot\left[I_{N}, I_{D}\right]
$$

In the second component of the perception/preference model $\delta_{N} \cdot I_{N}$ and $\delta_{D} \cdot I_{D}, I_{N}$ and $I_{D}$ are kept fixed and only vary with regard to the type of visualization the respondents are presented to in the choice sets. In these, the wind farms can be located at four different distances: $8 \mathrm{~km}, 12 \mathrm{~km}, 18$ $\mathrm{km}$, and $50 \mathrm{~km}$ from the coast. Accordingly, $I_{D}$ can take the values $I_{8}, I_{12}, I_{18}$, and $I_{50}$. In terms of visibility of the offshore wind farms, the wind farms at $8 \mathrm{~km}$ are more visible than the wind farms at $12 \mathrm{~km}$, etc., i.e., $I_{8}>I_{12}>I_{18}>I_{50}$. However, whether the respondents perceive the visibility of the wind farms at different distances from the shore as being negative, neutral, or positive, strongly depends on the learning parameter $\delta_{i}$, the prior information $\boldsymbol{B}_{i} \cdot \vartheta$, and the background characteristics $X_{i}$.

The focus of the present study is to explore how $\beta_{D} \cdot \vartheta_{D}$ and $\delta_{D} \cdot I_{D}$ are related. Especially, it aims to test if the visual information given to the respondents via the given visualizations changes the perception so that the stated WTP is interpreted as being in contrast to the previously stated perceptions of the visual impacts. To be more specific, this research question can be broken down into relations between perceptions and preferences, as discussed in the following paragraphs.

For respondents who have a positive perception $\beta_{D} \cdot \vartheta_{D}>0$, the visualization can confirm $\delta_{D} \cdot I_{D}>$ 0 (visualizations induce a positive perception of the visual impact) or weaken $\delta_{D} \cdot I_{D}<0$ (visualizations induce a negative perception of the visual impact) this perception. If the visualizations induce a negative perception that is equal to $\left|b_{D} \cdot \vartheta_{D}\right|=\left|\delta_{D} \cdot I_{D}\right|$ or stronger $\left|b_{D} \cdot \vartheta_{D}\right|<$ $\left|\delta_{D} \cdot I_{D}\right|$ than the initial perception, the respondents will state a zero or positive WTP for reducing the visual impacts from offshore wind farms, respectively.

For respondents with a neutral perception $B_{D} \cdot \vartheta_{D}=0$, the visualizations can confirm $\delta_{D} \cdot I_{D}=0$ (visualizations induce a neutral perception of the visual impact) or weaken $\delta_{D} \cdot I_{D}>0$ (visualizations induce a negative or positive perception of the visual impact) this perception. If $\delta_{D} \cdot I_{D}<0$, then the WTP for reducing the visual impacts will be positive and not the expected 'zero WTP'. If $\delta_{D} \cdot I_{D}>0$, then the WTP for reducing the visual impacts will be negative.

Finally, for the respondents with a negative perception $B_{D} \cdot \vartheta_{D}<0$, the visualization can confirm $\delta_{D} \cdot I_{D}<0$ (visualizations induce a negative perception of the visual impact) or weaken $\delta_{D} \cdot I_{D}>0$ (visualizations induce a positive perception of the visual impact) this perception. If the visualizations induce a positive perception that is equal to $\left|\beta_{D^{\cdot}} \vartheta_{D}\right|=\left|\delta_{D} \cdot I_{D}\right|$ or stronger $\left|b_{D^{\circ}} \vartheta_{D}\right|<$ $\left|\delta_{D} \cdot I_{D}\right|$ than the initial perception, the respondents will state a zero or negative WTP for reducing the visual impacts from offshore wind farms, respectively.

The tests for identical perceptions and preferences were carried out on groups of respondents. More specifically, the sample was divided into three groups, which represent the three types of initial perceptions of the visual impacts. While one group perceives the visual impacts to be positive (Positive Perception), a second group perceives the impacts to be neutral (Neutral Perception), and the last group perceives the impacts to be negative (Negative Perception). ${ }^{4}$ Based on this grouping, the following main $\left(\mathrm{H}_{0}\right.$ and $\left.\mathrm{H}_{2}\right)$ and sub-hypotheses $\left(\mathrm{H} 1 \mathrm{~A}_{0}, \mathrm{H}_{1} \mathrm{~B}_{0}\right.$, and $\left.\mathrm{H} 1 \mathrm{C}_{0}\right)$, are put forward:

$\mathrm{H} 1_{0}$ : Perception and preferences are equal:

\footnotetext{
${ }^{4}$ By dividing the respondents into these three distinct groups, we also eliminate the potential biases associated with respondents using scales differently with regards to "mainly" and "very" positive/negative impacts.
} 
$\mathrm{H} 1 \mathrm{~A}_{0}$ : Positive Perception respondents have negative preferences for reducing visual impacts from offshore wind farms, i.e., WTP Positive Perception $<0$

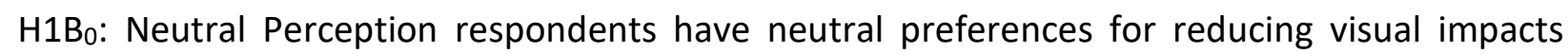
from offshore wind farms, i.e., WTP Neutral Perception $=0$

$\mathrm{H}_{1} \mathrm{C}_{0}$ : Negative Perception respondents have positive preferences for reducing visual impacts from offshore wind farms, i.e., WTP Negative Perception 0

$\mathrm{H} 1_{1}$ : Perception and preferences are not equal

Stated perceptions and preferences might not be expressed on the same scale. This could be a potential explanation for the rejection of $\mathrm{H} 1$. However, we would still expect the relative differences between perceptions and preferences to persist. Hence, it is expected that respondents who perceive the visual impacts to be positive have weaker preferences for reducing the visual impacts from offshore wind farms compared to respondents who perceive the impacts to be neutral or negative and so forth. An alternative hypothesis $\mathrm{H} 2$ is therefore defined as:

$\mathrm{H}_{\mathrm{o}}$ : WTP Positive Perception $<\mathrm{WTP}_{\text {Neutral Perception }}<\mathrm{WTP}_{\text {Negative Perception }}$

$\mathrm{H} 2_{1}$ : WTP Positive Perception $>$ WTP $_{\text {Neutral Perception }}><$ WTP $_{\text {Negative Perception }}$

Rejection of $\mathrm{H} 2$ suggests that there is no relation between prior perception of the visual impacts from offshore wind farms and the visualization guided preferences for reducing the visual impacts. Accordingly, the perceptions of the visual impacts from offshore wind farms seem to be updated by the use of visualizations, as argued in Hevia-Koch and Ladenburg [7].

\subsection{Parametric Analysis of the Link between Prior Perceptions and Updated Preferences}

The Mixed Logit model (MXL) is applied in the parametric analysis. MXL relies on McFadden's Random Utility Model [40]. In the CE, each respondent is asked to choose between two alternative layouts of Danish offshore wind power development. Under the assumption that respondent, $n$, chooses the alternative, which yields the highest utility, the systematic utility (V) can be expressed as:

$V_{n}=\beta_{1} \times D 1250_{n}+\beta_{2} \times D 18_{n}+\beta_{3} \times D 50_{n}+\beta_{4} \times S M_{n}+\beta_{5} \times S L_{n}+\beta_{6} \times \operatorname{COST}_{n}+\varepsilon_{n}(4)$

Where D1250 is used as a dummy variable controlling for locating the wind farms at distances $(12,18$, or $50 \mathrm{~km})$ beyond $8 \mathrm{~km}$ from the shore; D18 and D50 are dummy variables for locating the offshore wind farms at 18 and $50 \mathrm{~km}$, relative to $12 \mathrm{~km}$ from the shore; SM and SL are dummy variables representing medium (100 turbines) and large wind (144 turbines) farms relative to small wind farms (49 turbines); COST is the cost associated with an offshore location; and the $\beta 1$ to $\beta 6$ are the estimated utility/preference parameters.

As mentioned, the flexible MXL is used to estimate respondents' preferences for offshore wind farms. The MXL model imposes fewer restrictions than the conditional logit model (CL) by allowing random taste variation and substitution over alternatives [41]. Applying a more general but equivalent utility definition, the following MXL model is estimated:

$$
U_{n i t}=V_{\text {nit }}\left(x_{\text {nit }}\right)=\beta_{n}^{\prime} x_{\text {nit }}+\varepsilon_{\text {nit }}=\left(\beta+\varphi_{n}\right)^{\prime} x_{\text {nit }}+\varepsilon_{\text {nit }} \cdots \varepsilon_{\text {nit }} \sim I I D \text { extreme value }
$$

Where Unit is the utility, Vnit is the general systematic utility, $x_{\text {nit }}$ is a vector of the offshore wind farm attributes of alternative $I, t$ is choice task number [1-3] for individual $n, \beta$ is the mean 
attribute preference, while $\varphi_{n}$ is respondent $n$ 's deviation from the mean, $\beta$. The MXL model permits correlation in the stochastic part of the utility over alternatives, attributes, and choices, $\varphi_{n}{ }^{\prime} x_{n i t}+\varepsilon_{n i t}$. Conditional on $\beta_{n}$, the choice probability of respondent $\mathrm{n}$ 's choice of alternative $\mathrm{i}$ in choice set $\mathrm{t}$ is defined as

$$
L_{n i t}\left(\beta_{n}\right)=P\left(i \mid x_{n t}, \beta_{n}\right)=\frac{\exp \left(\beta_{n}^{\prime} x_{n i t}\right)}{\sum_{j=1}^{J} \exp \left(\beta_{n}^{\prime} x_{n i t}\right)}
$$

However, allowing for examination of unobserved preference heterogeneity through $\varphi_{n}$ implies that $\varphi_{n}$ is unknown to the researcher. It is, therefore, necessary for model identification to assume a distribution of $f\left(\beta_{n} \mid \theta\right)$. The MXL unconditional choice probability is then the integral of the conditional probability over all possible values of $\beta_{n}$ from the distribution of $\theta$ [41].

$$
Q_{n i t}\left(\theta^{*}\right)=\int L_{n i t}\left(\beta_{n}\right) f\left(\beta_{n} \mid \theta^{*}\right) d \beta_{n}
$$

The dummy variable (D1250) controlling for locating offshore wind farms at a distance beyond $8 \mathrm{~km}(12 \mathrm{~km}, 18 \mathrm{~km}$, or $50 \mathrm{~km})$ is set as a random parameter with a normal distribution in the MXL specification. This allows for the heterogeneity of preferences to be both positive and negative for the location of the wind farms. All other variables are kept fixed (nonrandom).

A MXL model is estimated for each group (Positive Perception, Neutral Perception, and Negative Perception). Using 1,000 Halton draws from the mixed distribution to simulate the loglikelihood function, maximum simulated likelihood estimation (MSLE) is used.

\subsubsection{Deriving Estimates of Willingness to Pay}

The focus of attention, when comparing perceptions and preferences, is on the potential difference in preferences/WTPs between respondents with different impact perceptions for reducing the visual impacts from offshore wind farms. Assuming utility maximization, the alternative is a trade-off between the attribute levels of each alternative, revealing the preferences of the respondents. If a monetary attribute is included in the CE, an estimate of WTP for the non-monetary attributes can be obtained by scaling the coefficient of interest with the coefficient representing the marginal utility of price and multiplying with -1 [42]:

$$
W T P_{x}=-\frac{\beta_{x}}{\beta_{C O S T}}
$$

Where $\beta x$ is the coefficient of the attribute of interest (D1250, D18, and D50) and $\beta$ COST is the cOST coefficient.

\section{Results}

The estimated preferences for each of the three perception groups are presented in Table 1. The associated WTPs are estimated for each visual perception group in Table 2. Twelve respondents out of the original 365 respondents in the survey, answered "Don't know" to the 
perception question. These are left out of the analyses, leaving a sample survey of a total of 353 respondents. Of these, 102, 164, and 87 respondents have a positive, neutral, or negative perception, respectively.

Table 1 Preferences for reducing visual impacts from offshore wind farms, MXL model.

\begin{tabular}{|c|c|c|c|}
\hline & $\begin{array}{l}\text { Positive Perception } \\
\text { Estimated parameter }\end{array}$ & $\begin{array}{l}\text { Neutral Perception } \\
\text { Estimated parameter }\end{array}$ & $\begin{array}{l}\text { Negative Perception } \\
\text { Estimated parameter }\end{array}$ \\
\hline \multicolumn{4}{|l|}{ Mean estimate } \\
\hline COST & $\begin{array}{l}-0.0395^{* * *} \\
{[0.00600]}\end{array}$ & $\begin{array}{l}-0.0436^{* * *} \\
{[0.00537]}\end{array}$ & $\begin{array}{l}-0.0539^{* * *} \\
{[0.00969]}\end{array}$ \\
\hline D1250 km & $\begin{array}{l}0.599^{*} \\
{[0.290]}\end{array}$ & $\begin{array}{l}0.485^{*} \\
{[0.231]}\end{array}$ & $\begin{array}{l}1.024^{*} \\
{[0.498]}\end{array}$ \\
\hline $\mathrm{D} 18 \mathrm{~km}^{\mathrm{a}}$ & $\begin{array}{l}0.382 \\
{[0.242]}\end{array}$ & $\begin{array}{l}0.950^{* * *} \\
{[0.213]}\end{array}$ & $\begin{array}{l}0.980^{* *} \\
{[0.335]}\end{array}$ \\
\hline $\mathrm{D} 50 \mathrm{~km}^{\mathrm{a}}$ & $\begin{array}{l}0.586^{*} \\
{[0.258]}\end{array}$ & $\begin{array}{l}1.225^{* * *} \\
{[0.246]}\end{array}$ & $\begin{array}{l}1.699^{* * *} \\
{[0.453]}\end{array}$ \\
\hline SL & $\begin{array}{l}-0.165 \\
{[0.204]}\end{array}$ & $\begin{array}{l}-0.251 \\
{[0.162]}\end{array}$ & $\begin{array}{l}-0.167 \\
{[0.263]}\end{array}$ \\
\hline SM & $\begin{array}{l}-0.0497 \\
{[0.212]}\end{array}$ & $\begin{array}{l}-0.111 \\
{[0.172]}\end{array}$ & $\begin{array}{l}0.211 \\
{[0.303]}\end{array}$ \\
\hline \multicolumn{4}{|l|}{ SD } \\
\hline D1250 km & $\begin{array}{l}1.028^{+} \\
{[0.607]}\end{array}$ & $\begin{array}{l}0.934^{+} \\
{[0.505]}\end{array}$ & $\begin{array}{l}2.299^{* *} \\
{[0.828]}\end{array}$ \\
\hline$N$ & 102 & 164 & 87 \\
\hline $\operatorname{LL}(0)$ & -211.4 & -340.3 & -180.9 \\
\hline $\operatorname{LL}(6)$ & -171.2 & -252.7 & -130.9 \\
\hline McFadden $R^{2}$ & 0.190 & 0.257 & 0.276 \\
\hline
\end{tabular}

Notes: ${ }^{a)}$ Relative to D1250 km. Standard errors in brackets: ${ }^{+} p<0.10,{ }^{*} p<0.05,{ }^{* *} p<0.01,{ }^{* * *}$ $p<0.001$.

Across the three models, the preferences for moving future offshore wind farms to locations farther than $8 \mathrm{~km}$ from the coast are significant. The joined variable for locating the wind farms at 12,18 , or $50 \mathrm{~km}$ from the shore is positive and significant on a $95 \%$ level of confidence in all three models $\left(B_{D 1250}>0\right)$. Accordingly, $\mathrm{H}_{1} \mathrm{~A}_{0}$ and $\mathrm{H}_{1} \mathrm{~B}_{0}$ are rejected, but not $\mathrm{H} 1 \mathrm{C}_{0}$. Interestingly, the estimated McFadden $\mathrm{R}^{2}$ seems to be lower among the respondents who have a positive perception of the visual impacts $\left(R^{2}=0.190\right)$, than those with a neutral and negative perception $\left(R^{2}=0.257\right.$ and 0.276$)$. This indicates that there is more variation in their stated preferences among respondents with a positive perception. This will be elaborated upon in the Discussion section. The rejection of $\mathrm{H}_{1} \mathrm{~A}_{0}$ and $\mathrm{H}_{1} \mathrm{~B}_{0}$ becomes even more apparent, when the WTPs among the 
three samples are compared in Table 2. The WTP estimates also allow us to test $\mathrm{H} 2_{0}$. Only the WTPs for locating the wind farms at $12 \mathrm{~km}, 18 \mathrm{~km}$, and $50 \mathrm{~km}$ from the shore are shown as the hypothesis relates to the distance from shore.

Table 2 Comparisons of WTPs between perception groups ( $€$ /household/year).

\begin{tabular}{|c|c|c|c|c|c|c|}
\hline & $\begin{array}{l}\text { Positive } \\
\text { Perception }\end{array}$ & $\begin{array}{l}\text { Neutral } \\
\text { Perception }\end{array}$ & $\begin{array}{l}\text { Negative } \\
\text { Perception }\end{array}$ & $\begin{array}{l}\text { Positive vs. } \\
\text { Neutral } \\
\text { Perception }^{d}\end{array}$ & $\begin{array}{l}\text { Positive vs. } \\
\text { Negative } \\
\text { Perception }{ }^{d}\end{array}$ & $\begin{array}{l}\text { Neutral vs. } \\
\text { Negative } \\
\text { Perception }^{d}\end{array}$ \\
\hline WTP $_{\text {Distance } 12}$ & $50.60^{*}$ & $37.17^{*}$ & $63.34^{*}$ & 13.43 & -12.73 & -26.17 \\
\hline $\mathrm{km}^{\mathrm{a}}$ & [24.75] & [17.87] & [30.29] & $(0.324)$ & $(0.375)$ & $(0.234)$ \\
\hline WTP $_{\text {Distance }} 18$ & $82.89^{* *}$ & $110.0^{* * *}$ & $124.0^{* * *}$ & -27.07 & -41.11 & -14.04 \\
\hline $\mathrm{km}^{\mathrm{b}}$ & [26.98] & [20.62] & [32.89] & $(0.218)$ & (0.169) & $(0.361)$ \\
\hline WTP $_{\text {Distance }} 50$ & $100.1^{* * *}$ & $131.0^{* * *}$ & $168.5^{* * *}$ & -30.90 & -68.32 & -37.42 \\
\hline $\mathrm{km}^{\mathrm{c}}$ & [26.55] & {$[20.83]$} & [33.59] & $(0.184)$ & $(0.056)$ & $(0.174)$ \\
\hline
\end{tabular}

Notes: ${ }^{\text {a) }} \mathrm{WTP}_{\text {Distance } 12 \mathrm{~km}}=\left(\beta_{\mathrm{D} 1250}\right) /-\beta_{\mathrm{COST}},{ }^{\text {b) }} \mathrm{WTP}_{\text {Distance } 18 \mathrm{~km}}=\left(\beta_{\mathrm{D} 1250}+\beta_{\mathrm{D} 18}\right) /-\beta_{\text {COST }},{ }^{\text {c) }}{ } \mathrm{WTP}_{\text {Distance } 50}$ $\left.\mathrm{km}=\left(\beta_{\mathrm{D} 1250}+\beta_{\mathrm{D} 50}\right) /-\beta_{\mathrm{COST}}\right)$. Difference in WTP is tested with the Poe test $[39,40]$. Standard errors in brackets: ${ }^{+} p<0.10,{ }^{*} p<0.05,{ }^{* *} p<0.01,{ }^{* * *} p<0.001$.

The respondents hold significant and positive WTPs; WTP Distance $12 \mathrm{~km}, W_{\text {TP }} P_{\text {Distance }} 18 \mathrm{~km}$, and WTP Distance $_{50 \mathrm{~km}}>0$. More specifically, independent of whether the respondents have stated a negative, neutral, or positive perception, the respondents have expressed positive and significant WTPs for reducing visual impacts from offshore wind farms by locating them at $12 \mathrm{~km}, 18 \mathrm{~km}$, or $50 \mathrm{~km}$ from the shore, relative to a location at $8 \mathrm{~km}$. Consequently, as mentioned before, $\mathrm{H}_{1} \mathrm{~A}_{0}$ and $\mathrm{H}_{1} \mathrm{~B}_{0}$ are rejected. A comparison of the levels of WTP for reduction of the visual impacts across the three perception groups tests $\mathrm{H} 2_{2}$. The comparison of WTP across the three perception groups strongly suggests that the WTPs for reducing the visual impacts from offshore wind farms are equal. We cannot reject equality in WTP using the Poe test $[43,44]$, except when comparing the WTP for locating the wind farms at $50 \mathrm{~km}$. In that case, the respondents with a positive perception have a significantly lower level of WTP when compared to respondents with a negative perception, although it is only 0.056 . Thus, $\mathrm{H}_{2}$ is also rejected.

\section{Discussion}

The results of the present paper suggest that initial perceptions about the visual impacts from offshore wind farms seem to be updated by the visualizations at different distances from the shore. As a result, independent of initial perceptions, all respondents have positive preferences and WTPs for reducing the visual impacts from offshore wind farms by locating them far from the shore. 
However, the methodological and estimation approach in the present study does not rest on a randomized experiment. There are several examples of experiments on wind power SP literature. Lutzeyer et al. [8] used a randomized experiment to test the impact of night light on offshore wind farms on the WTP for offshore wind farm locations. In an experiment, Ladenburg et al. [32] tested the impact of economic incentive reminders on stated preferences for offshore wind farm locations. The study found that giving respondents a Cheap Talk, had little influence on preferences. Another study, also focusing on the visual presentation of wind farms in $\mathrm{CE}$, is the one done by Hevia-Koch and Ladenburg [45]. They tested the influence of screen size on preferences for onshore wind power locations. They found that smaller screens are associated with lower WTPs. In our case, an ideal setup would be to compare preferences with and without the use of visual aids. This calls for further research.

That the model variance seems to be decreasing as a function of the respondents' prior perception is an interesting result. The more negative the perception (going from positive to neutral to negative), the lower is the model variance (McFadden $R^{2}$ higher). This points to the fact that though the respondents with a positive perception have been updated in their perception of the visual impacts from offshore wind farms by the visualizations, they are more ambiguous in their preferences. This suggests that the information in the visualizations influences the preferences of the respondents differently.

Information on the level of certainty in the choices the respondents have made is utilized [46, 47] to explore this further. After making the three choices, the respondents were asked to state their levels of certainty in the choices they made on a scale from 0 to 10 . Zero represents very uncertain and 10 means very certain. Table 3 shows the distribution of certainty levels.

Table 3 Distribution of certainty in choice levels across perception groups.

\begin{tabular}{llll}
\hline Level of certainty & $\begin{array}{l}\text { Positive } \\
\text { Perception }\end{array}$ & $\begin{array}{l}\text { Neutral } \\
\text { Perception }\end{array}$ & $\begin{array}{l}\text { Negative } \\
\text { Perception }\end{array}$ \\
\hline $0-3$ & $10 \%$ & $12 \%$ & $13 \%$ \\
$4-5$ & $14 \%$ & $16 \%$ & $15 \%$ \\
6 & $7 \%$ & $7 \%$ & $3 \%$ \\
7 & $17 \%$ & $21 \%$ & $17 \%$ \\
8 & $33 \%$ & $20 \%$ & $26 \%$ \\
9 & $10 \%$ & $15 \%$ & $15 \%$ \\
10 & $10 \%$ & $9 \%$ & $10 \%$ \\
\hline
\end{tabular}

The differences in the levels of certainty are not perfectly mirrored in the McFadden $\mathrm{R}^{2}$. Only $20 \%$ of the Positive Perception respondents have stated certainty of 9 or 10 , while this is $24 \%$ and $25 \%$, respectively, for the Neutral and Negative Perception groups. On the other hand, $33 \%$ of the respondents in the Positive Perception group have a certainty level of 8 , while this is $20 \%$ and $36 \%$, respectively, in the two other groups. However, it would be interesting to explore if differences in preferences and WTPs can be found among the respondents who are most certain in their choices. Again, under the assumption that prior perception correlates with preferences/WTPs, it could be expected that the stated level of certainty strengthens this correlation. More specifically, we would expect that the most certain respondents in the Positive, Neutral, and Negative Perception 
groups have negative, zero, and positive WTPs for locating wind farms that are $12 \mathrm{~km}, 18 \mathrm{~km}$, or $50 \mathrm{~km}$ from the shore, respectively. The estimated preferences, parameters, and WTPs among respondents with a certainty level of 8,9 , or 10 are shown in Table 4 . As the number of observations within each perception group is approximately halved, the model is estimated with only the $D 1250 \mathrm{~km}$ distance variable-the two dummy variables for the size of the wind farms and the cost attribute.

Table 4 Preferences and WTPs for reducing visual impacts from offshore wind farms, MXL model, certain respondents.

\begin{tabular}{llll}
\hline & $\begin{array}{l}\text { Positive Perception } \\
\text { Estimated parameter }\end{array}$ & $\begin{array}{l}\text { Neutral Perception } \\
\text { Estimated parameter }\end{array}$ & $\begin{array}{l}\text { Negative Perception } \\
\text { Estimated parameter }\end{array}$ \\
\hline Mean estimate & & & \\
& & & \\
COST & $-0.0341^{* * *}$ & $-0.0360^{* * *}$ & $-0.0475^{* * *}$ \\
& {$[0.00774]$} & {$[0.00674]$} & {$[0.0106]$} \\
D1250 km & $1.298^{* *}$ & $1.705^{* * *}$ & $2.126^{* *}$ \\
& {$[0.482]$} & {$[0.513]$} & {$[0.761]$} \\
SL & -0.140 & -0.0786 & -0.478 \\
& {$[0.297]$} & {$[0.252]$} & {$[0.406]$} \\
SM & -0.170 & $-0.437^{+}$ & -0.656 \\
\hline SD & {$[0.295]$} & {$[0.235]$} & {$[0.415]$} \\
D1250 km & 1.020 & & $1.728^{+}$ \\
\hline WTP D1250 $[€]$ & $127.03^{*}$ & 0.516 & {$[1.048]$} \\
\hline$N$ & {$[51.70]$} & {$[1.729]$} & $149.38^{* * *}$ \\
LL(0) & 53 & $157.90^{* * *}$ & {$[48.25]$} \\
LL(6) & -111.6 & {$[48.63]$} & 45 \\
McFadden $R^{2}$ & 0.197 & 73 & -93.6 \\
\hline
\end{tabular}
Notes: Standard errors in brackets: ${ }^{+} p<0.10,{ }^{*} p<0.05,{ }^{* *} p<0.01,{ }^{* * *} p<0.001$.

As the results strongly point, $\mathrm{H} 1$ and $\mathrm{H} 2$ are rejected among the respondents who are very certain in their choices. The estimated WTPs for locating the offshore wind farms at $12 \mathrm{~km}, 18 \mathrm{~km}$, or $50 \mathrm{~km}$ from the shore are between 127 and $158 € /$ household/year. The Poe tests of equality in WTPs are not significant. The results from the uncertain respondents are shown in Table 5. They show the same picture, though the estimated WTPs for locating the offshore wind farms at $12 \mathrm{~km}$, $18 \mathrm{~km}$, or $50 \mathrm{~km}$ from shore are generally lower and less significant. The Poe tests of equality in WTPs are not significant. $\mathrm{H} 1$ and $\mathrm{H} 2$ are thus also rejected among the respondents, who are very uncertain in their choices. 
Table 5 Preferences and WTPs for reducing visual impacts from offshore wind farms, MXL model, uncertain respondents.

\begin{tabular}{llll}
\hline & $\begin{array}{l}\text { Positive Perception } \\
\text { Estimated parameter }\end{array}$ & $\begin{array}{l}\text { Neutral Perception } \\
\text { Estimated parameter }\end{array}$ & $\begin{array}{l}\text { Negative Perception } \\
\text { Estimated parameter }\end{array}$ \\
\hline Mean estimate & & & \\
& & & \\
COST & $-0.0409^{* * *}$ & $-0.0384^{* * *}$ & $-0.0334^{* * *}$ \\
& {$[0.00873]$} & {$[0.00595]$} & {$[0.00905]$} \\
D1250 km & 0.433 & $0.578^{* *}$ & $0.793^{+}$ \\
& {$[0.324]$} & {$[0.196]$} & {$[0.471]$} \\
SL & -0.152 & $-0.352^{+}$ & -0.205 \\
& {$[0.289]$} & {$[0.193]$} & {$[0.313]$} \\
SM & -0.0564 & -0.255 & 0.105 \\
& {$[0.302]$} & {$[0.199]$} & {$[0.317]$} \\
\hline SD & & & 0.984 \\
D1250 km & 0.798 & 0.00105 & {$[1.046]$} \\
\hline \multirow{2}{*}{ WTP D1250 $(€)$} & {$[0.891]$} & {$[0.521]$} & $79.18^{+}$ \\
\hline$N$ & 35.33 & $50.27^{* *}$ & {$[46.37]$} \\
\hline LL(0) & {$[25.29]$} & {$[17.94]$} & 42 \\
LL(6) & 48 & 91 & -87.3 \\
\hline McFadden $R^{2}$ & -99.8 & -188.5 & -73.6 \\
\hline
\end{tabular}

Notes: Standard errors in brackets ${ }^{+} p<0.10,{ }^{*} p<0.05,{ }^{* *} p<0.01,{ }^{* * *} p<0.001$.

\section{Conclusion}

Based on a national sample of 353 respondents, perception of visual impacts from offshore wind farms and visualization-guided preferences/WTP for reducing visual impacts, are compared. The comparison is carried out by first asking the respondents about the perception of the visual impacts from offshore wind farms; then, they are given visualizations of offshore wind farms at different distances from the shore and asked to state their preferences/WTP for locating the wind farms at those distances. The results denote that respondents who perceive the same visual impacts as positive, neutral, or negative, have equally high and positive WTPs for the location of offshore wind farms at $12 \mathrm{~km}, 18 \mathrm{~km}$, or $50 \mathrm{~km}$ from the shore. More specifically, the WTPs across the three groups are between 37-63€, 83-124€, and 100-168€ for locating the offshore wind farms at $12 \mathrm{~km}, 18 \mathrm{~km}$, and $50 \mathrm{~km}$, respectively. For WTPs locating the wind farms at different distances, there are no significant differences across the three perception groups. However, there is an exception in comparing the WTP for locating the wind farms at $50 \mathrm{~km}$. In that case, the respondents with a positive perception have a significantly lower WTP when compared to 
respondents with a negative perception, although it is only 0.056 . These results suggest that the respondents with a positive or neutral prior perception of the visual impacts from offshore wind farms have had their prior knowledge of the visual impacts updated by the visualizations.

The results are robust even if we condition the analysis on whether the respondent has been certain or not in the choices of offshore wind farm location. These results are noteworthy, as they imply that policy decisions with regard to the level of reducing visual impacts from offshore wind farms could be very different and depend upon the type of information available.

\section{Acknowledgement}

The authors would like to thank the comments from three anonymous reviewers and from Director Maria Skotte (CLEAN Environment). Any errors are naturally the sole responsibility of the authors.

\section{Author Contributions}

Jacob Ladenburg has carried out all parts of the paper

\section{Funding}

This paper was written as part of project 1305-00021B under the Danish Council for Strategic Research and project 0602-00205B under the Danish Agency for Science, Technology, and Innovation.

\section{Competing Interests}

The author has declared that no competing interests exist.

\section{References}

1. IEA. Offshore wind outlook 2019. Paris: IEA; 2019. Available from: https://www.iea.org/reports/offshore-wind-outlook-2019

2. Gibbons S. Gone with the wind: Valuing the visual impacts of wind turbines through house prices. J Environ Econ Manage. 2015; 72: 177-196.

3. Jensen CU, Panduro TE, Lundhede TH. The vindication of Don Quixote: The impact of noise and visual pollution from wind turbines. Land Econ. 2014; 90: 668-682.

4. Ladenburg J, Lutzeyer S. The economics of visual disamenity reductions of offshore wind farms-Review and suggestions from an emerging field. Renew Sustain Energ Rev. 2012; 16: 6793-6802.

5. Rand J, Hoen B. Thirty years of North American wind energy acceptance research: What have we learned? Energ Res Soc Sci. 2017; 29: 135-148.

6. Sunak Y, Madlener R. The impact of wind farm visibility on property values: A spatial difference-in-differences analysis. Energ Econ. 2016; 55: 79-91.

7. Hevia-Koch P, Ladenburg J. Where should wind energy be located? A review of preferences and visualisation approaches for wind turbine locations. Energ Res Soc Sci. 2019; 53: 23-33.

8. Lutzeyer S, Phaneuf DJ, Taylor LO. The amenity costs of offshore wind farms: Evidence from a 
choice experiment. Energ Econ. 2018; 72: 621-639.

9. Pohl J, Faul F, Mausfeld R. Belästigung durch periodischen schattenwurf von windenergieanlagen. Kiel: Institut für Psychologie der Christian-Albrechts-Universität zu Kiel; 1999.

10. Rudolph D, Kirkegaard J, Lyhne I, Clausen NE, Kørnøv L. Spoiled darkness? Sense of place and annoyance over obstruction lights from the world's largest wind turbine test centre in Denmark. Energ Res Soc Sci. 2017; 25: 80-90.

11. Arrows K, Solow R, Paul P, Leamer EE, Radner R, Schuman H. Report of the NOAA panel on contingent valuation. Fed Regist. 1993; 58: 4601-4614.

12. Bateman I, Carson R, Day B, Hanemann M, Hanley N, Hett $T$, et al. Economic valuation with stated preference techniques. Cheltenham: Edward Elgar Publishing; 2002. Available from: https://www.elgaronline.com/view/1840649194.xml

13. Champ P, Boyle K, Brown T. A primer on nonmarket valuation. Dordrecht: Springer Netherlands; 2017. Available from: http://link.springer.com/10.1007/978-94-007-7104-8

14. Hoehn JP, Randall A. The effect of resource quality information on resource injury perceptions and contingent values. Resour Energ Econ. 2002; 24: 13-31.

15. Czajkowski M, Hanley N, Lariviere J, Simpson K. What is the causal effect of information and learning about a public good on willingness to pay? Stirling: Stirling Economics Discussion Paper; 2014. p 1-30.

16. Kataria M, Bateman I, Christensen T, Dubgaard A, Hasler B, Hime S, et al. Scenario realism and welfare estimates in choice experiments - A non-market valuation study on the European water framework directive. J Environ Manag. 2012; 94: 25-33.

17. Carlson R, Chandler $P$, Sweller J. Learning and understanding science instructional material. J Educ Psychol. 2003; 95: 629-640.

18. Hoehn JP, Lupi F, Kaplowitz MD. Stated choice experiments with complex ecosystem changes: The effect of information formats on estimated variances and choice parameters. J Agric Resour Econ. 2010; 35: 568-590.

19.Shr YH, Ready R, Orland B, Echols S. How do visual representations influence survey responses? Evidence from a choice experiment on landscape attributes of green infrastructure. Ecol Econ. 2019; 156: 375-386.

20. Patterson Z, Darbani JM, Rezaei A, Zacharias J, Yazdizadeh A. Comparing text-only and virtual reality discrete choice experiments of neighbourhood choice. Landsc Urban Plan. 2017; 157: 63-74.

21. Rid W, Haider W, Ryffel A, Beardmore B. Visualisations in choice experiments: Comparing 3d film-sequences and still-images to analyse housing development alternatives. Ecol Econ. 2018; 146: 203-217.

22. Matthews $Y$, Scarpa R, Marsh D. Using virtual environments to improve the realism of choice experiments: A case study about coastal erosion management. J Environ Econ Manage. 2017; 81: 193-208.

23. Ladenburg J, Dubgaard A, Martinsen L, Trandberg J. Economic valuation of the visual externalities of off-shore wind farms. Copenhagen. 2005; 1: 179.

24. Ladenburg J, Dubgaard A. Willingness to pay for reduced visual disamenities from offshore wind farms in Denmark. Energ Policy. 2007; 35: 4059-4071.

25. Adamowicz W, Louviere J, Williams M. Combining revealed and stated preference methods 
for valuing environmental amenities. J Environ Econ Manage. 1994; 26: 271-292.

26. Louviere JJ, Woodworth G. Design and analysis of simulated consumer choice or allocation experiments: An approach based on aggregate data. J Mark Res. 1983; 20: 350-367.

27. Knapp L, Ladenburg J. How spatial relationships influence economic preferences for wind power-A review. Energies. 2015; 8: 6177-6201.

28. Lancaster KJ. A new approach to consumer theory. J Polit Econ. 1966; 74: 132-157.

29. Rosen S. Hedonic prices and implicit markets: Product differentiation in pure competition. J Polit Econ. 1974; 82: 34-55.

30. Denmark. Miljø- og energiministeriet. Energy 21: The Danish government's action plan for energy 1996. Danish Ministry of Environment and Energy; 1996.

31. Cummings RG, Taylor LO. Unbiased value estimates for environmental goods: A cheap talk design for the contingent valuation method. Am Econ Rev. 1999; 89: 649-665.

32. Ladenburg J, Bonnichsen O, Dahlgard JO. Testing the effect of a short cheap talk script in choice experiments. Danish J Econ. 2011; 149: 25-54.

33. Blomquist GC, Whitehead JC. Resource quality information and validity of willingness to pay in contingent valuation. Resour Energ Econ. 1998; 20: 179-196.

34. Cerda AA, Garcia LY, Pastén RA, Damino IA, Diaz MT. The effects of visual information on willingness to pay for a recreational site improvement in Chile. Innovar. 2014; 24: 141-148.

35. Meyers-Levy J. Gender differences in information processing: A selectivity interpretation. Cognitive and affective responses to advertising. Lexington, MA: Lexington Books/DC Heath \& Com; 1989: p. 219-260.

36. Ertac S. Does self-relevance affect information processing? Experimental evidence on the response to performance and non-performance feedback. J Econ Behav Organ. 2011; 80: 532545.

37. Tkac J. The effects of information on willingness-topay values of endangered species. Am J Agric Econ. 1998; 80: 1214-1220.

38. Ladenburg J. Dynamic properties of the preferences for renewable energy sources $-A$ wind power experience-based approach. Energy. 2014; 76: 542-551.

39. Michell RC, Carson RT. Using surveys to value public goods: The contingent valuation method. Washington DC: Resources for the Future; 1989.

40. McFadden D. Conditional Logit analysis of qualitative choice behavior. Frontiers in Econometrics. New York: Academic Press; 1974. p. 105-142.

41. Train K. Discrete choice methods with simulation. Cambidge: Cambridge University Press; 2003.

42. Louviere JJ, Hensher DA, Swait JD. Stated choice methods: Analysis and applications, analysis and applications. Cambridge UK: Cambridge University Press; 2000.

43. Poe GL, Giraud KL, Loomis JB. Computational methods for measuring the difference of empirical distributions. Am J Agric Econ. 2005; 87: 353-365.

44. Poe GL, Severance-Lossin EK, Welsh MP. Measuring the difference ( $X-Y)$ of simulated distributions: A convolutions approach. Am J Agric Econ. 1994; 76: 904-915.

45. Hevia-Koch $P$, Ladenburg J. Is willingness to pay for visualised landscape amenities sensitive to screen size when using web surveys. Proceeding of 33rd USAEE/IAEE North American conference; 2015 October 25-28; Pittsburg, Pennsylvania, USA.

46. Regier DA, Watson V, Burnett H, Ungar WJ. Task complexity and response certainty in discrete 
choice experiments: An application to drug treatments for juvenile idiopathic arthritis. J Behav Exp Econ. 2014; 50: 40-49.

47. Mattmann M, Logar I, Brouwer R. Choice certainty, consistency, and monotonicity in discrete choice experiments. J Environ Econ Policy. 2019; 8: 109-127.

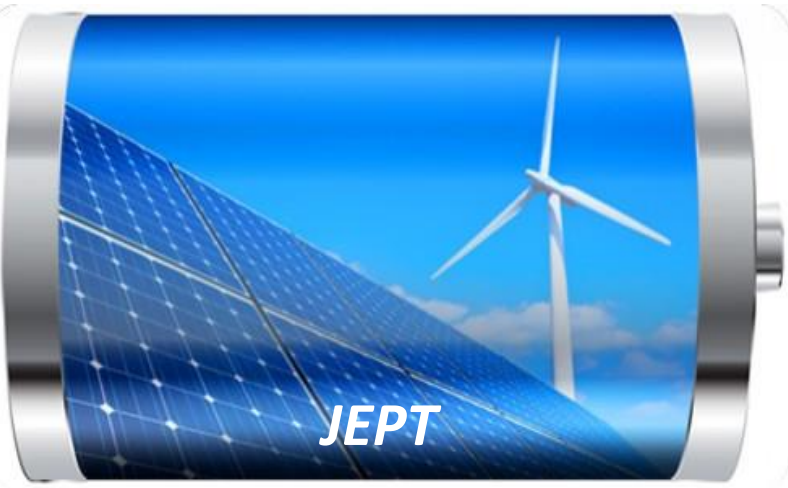

Enjoy JEPT by:

1. Submitting a manuscript

2. Joining in volunteer reviewer bank

3. Joining Editorial Board

4. Guest editing a special issue

For more details, please visit:

http://www.lidsen.com/journal/jept 